\title{
REGGAE MUSIC COMMUNITY PRACTICE IN THE CITY OF BONTANG (DESCRIPTIVE STUDY OF BONTANG REGGAE COMMUNITY)
}

\section{PRAKTIK KOMUNITAS MUSIK REGGAE DI KOTA BONTANG (STUDI DESKRIPTIF BONTANG REGGAE COMMUNITY)}

\author{
Muhammad Fachmi Syafa ${ }^{1}$, Sri Murlianti \\ Universitas Mulawarman, Indonesia \\ Email Correspondence: syafafahmy@gmail.com
}

\begin{abstract}
:
This study describes the practice of social life in the field of music in the city of Bontang, based on a sociological perspective using the generative formulation of the theory of Pierre Bourdieu (Habitus x Modal) + Ranah $=$ Practice. This shows that the existence of the Bontang Reggae Community has produced several groups consisting of Reggae Grill, Slow Reggae, and Reggae Vibe groups as actors who practice in the realm of reggae music. This group was formed because of the different knowledge and understanding in the field of reggae music as a realm of space for social life, which then produced various habitus according to the realm of music in each group. Also, the existence of each group has been supported by the existence of a classification of capital which according to Bourdieu consists of four fundamental capitals including material capital, social capital, cultural capital, and symbolic capital. The three groups produce a practice resulting from dialectical relations through habitus-modal interactions in different and prominent domains of reggae music. The Reggae Grill group produces practices that come from symbolic capital, and circular habitus or the use of Cannabis, then the Slow Reggae group produces modern music practices that come from material capital and cultural capital, and the Reggae Vibe group produces solidarity practices that come from cultural capital and capital. symbolic, as well as group habitus.
\end{abstract}

Keywords: Community, Habitus, Reggae Community, Reggae Music

\begin{abstract}
ABSTRAK:
Penelitian ini menggambarkan praktik kehidupan sosial masyarakat pada bidang seni musik di kota Bontang, berdasarkan perspektif sosiologi dengan menggunakan rumusan generatif teori Pierre Bourdieu (Habitus x Modal) + Ranah $=$ Praktik . Menunjukkan bahwa keberadaan Bontang Reggae Community telah melahirkan beberapa kelompok yang terdiri dari kelompok Reggae Grill, Slow Reggae, dan Reggae Vibe sebagai aktor yang melakukan praktik dalam ranah kehidupan seni musik reggae. Kelompok ini terbentuk karna adanya pengetahuan dan pemahaman yang berbeda-beda di bidang seni musik reggae sebagai ranah atau ruang kehidupan sosial, yang kemudian menghasilkan berbagai habitus sesuai dengan ranah musik pada masing-masing kelompok. Selain itu, keberadaan setiap kelompok telah didukung dengan adanya klasifikasi modal yang menurut Bourdieu terdiri dari keempat modal fundamental diantaranya adalah, modal material, modal sosial, modal kultural, dan modal simbolik. Ketiga kelompok tersebut menghasilkan sebuah praktik yang dihasilkan dari hubungan dialektis melalui interaksi habitus-modal dalam ranah musik reggae yang berbeda dan menonjol. Kelompok Reggae Grill menghasilkan praktik yang bersumber dari modal simbolik, dan habitus melingkar atau penggunaan Cannabis, kemudian kelompok Slow Reggae menghasilkan praktik musik modern yang bersumber dari modal material dan modal budaya, serta kelompok Reggae Vibe menghasilkan praktik solidaritas yang bersumber dari modal budaya, dan modal simbolik, serta habitus berkelompok.
\end{abstract}

Kata Kunci: Habitus, Komunitas, Musik Reggae, Reggae Community

\section{Article Info}

Received

July 2020

Accepted

July 2020

Published

DOI

$$
\text { July } 2020
$$

https://doi.org/10.30872/psd.v1i2.21

\section{Copyright and License}

Authors retain copyright and grant the journal right of first publication with the work simultaneously licensed under a Creative Commons Attribution 4.0 International License that allows others to share the work with an acknowledgment of the work's authorship and initial publication in this journal. 


\section{PENDAHULUAN}

Musik adalah salah satu bentuk hasil karya manusia yang terus berkembang, perkembangan musik sendiri bisa dikatakan sangat berkaitan dengan perkembangan kondisi sosial dalam masyarakat. Musik dan masyarakat adalah dua hal yang saling mempengaruhi, karena bisa dikatakan menjadi sebuah kebutuhan dan salah satu bentuk budaya yang terus berkembang.

Reggae merupakan aliran/genre musik yang berasal dari kota Kingston, negara Jamaika yang di populerkan oleh Robert Nesta Marley atau yang biasa dikenal dengan nama Bob Marley dan band nya The Wailers. Musik reggae lahir pada tahun 1968, kelahiran musik reggae dipengaruhi oleh aliran musik Ska dan Rocksteady yang pada saat itu masyarakat Jamaika lebih menyukai musik bertempo lambat dan bermakna bagi kehidupan sosial, yang sedang mengalami tekanan dan kemudian mempengaruhi musik. Musik reggae juga di pengaruhi oleh ajaran Rastafari, hal ini dikarenakan ada banyak musisi reggae termasuk anggota Wailers, dan Bunny wailer yang tercatat sebagai rastafarian. Rasta atau Gerakan Rastafari, adalah sebuah gerakan atau agama baru yang mengakui Haile Selassie I, mendiang kaisar Ethiopia, sebagai raja diraja, Tuan dari segala tuan dan singa yehuda sebagai Jah (panggilan Tuhan bagi kaum Rastafari).

Gerakan ini muncul di Jamaika di antara kaum kulit hitam kelas pekerja dan petani yang berada pada kelas sosial paling bawah, sementara kaum kulit putih dan agama mereka berada di paling atas. Hal tersebut kemudian melahirkan bentuk perlawanan dari kaum rastafari yang mengedepankan kemurnian hidup, penuh cinta dan tanpa kemarahan. Kaum rastafarian meyakini bahwa hidup dengan alam dan menjadi bagian dari alam merupakan bentuk sifat mereka, termasuk rambut gimbal, ganja (marijuana), makanan ital dan segala aspek kehidupan non-modern.

Musik reggae dikenal di Indonesia sekitar tahun 1980, diawali dengan munculnya band Reggae Abreso (seluruh Personilnya berasal dari papua) yang dimana berasal dari kaum kulit hitam di Indonesia saat acara Reggae Night di taman Impian ancol. Kemudian di susul dengan lagu ciptaan mendiang melky goeslaw berjudul "Reggae Pribumi" yang memperkenalkan reggae ke masyarakat umum Dan seterusnya bermunculan band band reggae di tahun 1986 yaitu black company, hingga beberapa tahun berikutnya band reggae Asian Roots, Asian force dan band band reggae yang saat ini sudah populer sejak lama, seperti Imanez, Steven Jam, Tony Q Rastafara dan masih banyak lagi. Hingga saat ini musik reggae berhasil menelurkan penggemar dan komunitas komunitas yang ada diberbagai kota, seperti Jogjakarta Reggae Community, Jakarta Reggae Comunity, Bali Reggae Community, hingga di Kalimantan Timur ada Balikpapan Reggae community, Samarinda Reggae Community, termasuk Kota Bontang yang menjadi objek penelitian penulis yaitu Bontang Reggae Community.

Ketika musik Reggae semakin digemari oleh banyak kalangan masyarakat di Indonesia, maka musik Reggae akan cepat tersebar dan berkembang diseluruh kota-kota di Indonesia. Misalnya saja perkembangan musik Reggae di kota Bontang. Perkembangan musik reggae di kota Bontang dirasa sangat menarik, karena selain sebagai kota kecil justru musik yang dipandang sebagai musik minoritas ini dapat terus berkembang dan mempertahankan keberadaannya di kota Bontang. Representasi dari berkembangnya musik reggae di Kota Bontang ditunjukkan dengan adanya komunitas Reggae di kota ini. Komunitas musik Reggae di kota Bontang sendiri di kenal dengan nama Bontang reggae Community.

Bontang Reggae Community adalah komunitas yang tergolong kelompok minoritas dengan pandangan yang negatif melihat fashion dan lifestyle anak-anak Reggae yang urak-urakan, rambut gimbal, pakaian lusuh dan kendaraan alakadarnya. Tetapi dengan adanya reggae telah memberi warna baru, dan hal tersebut yang membuat komunitas ini tidak ada yang menyamainya. Secara tidak langsung, Bontang Reggae Community juga bisa dikatakan satu-satunya organisasi sosial yang membawahi musik reggae didalamnya. Dua ciri musik yang paling penting dari organisasi sosial musik adalah : Status dan Peran: prestise pembuat musik, dan peran-peran berbeda yang di berikan masyarakat pada budaya-musik (Sunarto, 2007, 4).

Dengan adanya stigma yang berkembang dalam masyarakat yang cenderung menganggap musik Reggae sebagai musik minoritas, justru dengan adanya Bontang Reggae Community, musik reggae tidak akan kalah bersaing dengan jenis-jenis musik lain yang mulai berkembang dan populer di kota Bontang. Melihat fakta sosial yang bertentangan inilah sehingga kemudian perlu diungkap bagaimana sebuah komunitas dengan materi musik yang bersifat minoritas dapat berkembang dan bertahan dalam ranah musik di kota Bontang. Maka dari itu penulis mengambil penelitian tentang Praktik Komunitas Musik Reggae di Kota Bontang untuk mengetahui dan mendeskripsikan lebih jauh mengenai keberadaan Bontang Reggae Community dengan berbagai macam praktik didalamnya.

\subsection{Habitus}

Habitus merupakan suatu kebiasaan masyarakat yang melekat pada diri seseorang dalam bentuk posisi abadi, atau kapasitas terlatih dan kecendrungan terstruktur untuk berfikir, merasa dan bertindak dengan cara determinan. Habitus merupakan hasil keterampilan yang menjadi tindakan praktis (tidak selalu disadari) yang diterjemahkan menjadi kemampuan yang terlihat alamiah. 


\subsection{Modal}

Modal merupakan hubungan sosial yang artinya suatu energi sosial hanya ada dan membuahkan hasilhasil dalam arena perjuangan dimana ia memproduksi dan diproduksi. Modal merupakan konsentrasi kekuatan spesifik yang beroperasi dalam ranah dan setiap ranah menuntut individu untuk memiliki modal khusus agar dapat hidup secara proporsional dan bertahan di dalamnya. Ada 4 jenis modal fundamental bagi Bourdieu (Ritzer \& Goodman, 2004:525-526) modal ekonomi (yang berasal dari pemberdayaan ekonomi), modal sosial (terdiri dari hubungan sosial yang bernilai antara individu), modal kultural (meliputi berbagai pengetahuan yang sah) dan

\subsection{Ranah}

Ranah adalah ruang khusus dalam masyarakat yang memiliki kekuatan parsial dan bersifat otonom, sekaligus berlangsung didalamnya perjuangan posisi-posisi dalam melakukan suatu tindakan dan sebagai sarana persaingan dan perjuangan yang sifatnya dinamis. modal simbolik (berasal dari kehormatan dan prestise seseorang). Dari ke empat modal tersebut tentu harus dimiliki oleh individu yang tergabung dalam suatu ranah.

\subsection{Praktik}

Praktik merupakan hasil akhir yang bersifat dialektis melalui interaksi habitus-modal dalam suatu ranah tertentu yang dilakukan oleh individu/kelompok.

\subsection{Pengumpulan, Pengunaan, dan Pengalihan Modal}

Modal adalah sesuatu yang memungkinkan individu memenangkan pertarungan dalam ranah dan tentunya harus dimiliki oleh individu yang terlibat dalam sebuah ranah agar dapat mencapai tujuan. Untuk mendapatkan serta mengumpulkan suatu modal perlu adanya proses dan cara yang berbeda beda. Semisal, untuk mendapatkan suatu kekuasaan atau posisi sosial yang tinggi dalam suatu ranah, individu harus memiliki macam-macam modal yang menurut dia dapat menunjang keberhasilannya dalam menempati posisi kekuasaan. contohnya, modal sosial dan modal materi. Modal sosial yang dimiliki yaitu jaringan sosial yang kuat untuk mendukung individu dalam memperoleh kekuasaan dan modal materi merupakan alat yang kuat untuk menjamin keberasilan.

Begitupun dalam praktik komunitas musik Reggae, dalam suatu ranah kehidupan tersebut tentu perlu adanya modal yang harus dimiliki setiap individu yang terlibat didalamnya yang didapatkan melalui proses pembelajaran, usaha mengumpulkan materi berupa uang, hasil komunikasi sosial sesama penikmat musik, dan lain nya. Contohnya suatu band yang bernaung dalam komunitas tersebut, tentu ada proses pembelajaran yang dimiliki untuk meningkatkan kreatifitas dan mendapatkan inovasi dalam bermusik, selain itu mereka juga membutuhkan dukungan modal alat musik dengan kualitas yang terbaik.

\subsection{Komunitas Musik Reggae sebagai Ranah Kehidupan}

Ranah adalah ruang sosial yang melibatkan setiap individu dapat terlibat dalam dunia sosial. Maksud dari ranah disini adalah sebagai arena setiap individu dalam melakukan praktik sosialnya untuk mendapatkan posisi sosial yang terstruktur melalui habitus dan modal yang dimiliki. Seluruh tindakan individu yang dilakukan dalam ranah sosial merupakan arena perjuangan kelas untuk dapat bersaing agar mampu mendominasi. Keberhasilan aktor tergantung pada struktur modal yang dimiliki dalam lingkup sosial tersebut untuk memperoleh posisi sosial dalam ranah. Ranah yang dimaksud disini adalah Bontang Reggae Community, salah satu komunitas yang memiliki banyak anggota dan memiliki potensi dalam keahlian bermusik Reggae dilihat dari beberapa band yang bernaung dibawah komunitas Reggae.

\section{METODE}

Penelitian ini menggunakan model penelitian Kualitatif, yakni sebuah penelitian yang cenderung menggunakan suatu analisis deskriptif. Harapannya metode ini mampu mengungkapkan dan memperoleh informasi secara mendalam, dan mendetail dari informan untuk mengungkap permasalahan yang ada dalam masyarakat. Menurut Lofland dalam (Moleong 2012: 157).

\section{HASIL DAN PEMBAHASAN}

Pertumbuhan Komunitas Musik Reggae di Kota Bontang Reggae Community merupakan salah satu kelompok kecil yang hadir di tengah-tengah masyarakat kota Bontang yang terbentuk pada tahun 2012, sebagai sebuah perkumpulan atau komunitas musik yang bergenre khusus Reggae. Sama seperti kelompok masyarakat pada umumnya, Bontang Reggae Community merupakan kelompok sosial yang menghasilkan berbagai praktik. Dalam kelompok tersebut terdiri dari adanya modal, ranah, dan habitus yang dimiliki oleh masing-masing individu agar dapat memperjuangkan posisinya didalam suatu ranah yaitu ranah musik 
Reggae. Dalam setiap aktivitasnya, kelompok ini selalu berusaha untuk terus mempertahankan keberadaannya di Kota Bontang, agar musik Reggae yang mereka tampilkan dapat dikenal oleh masyarakat luas khususnya di Kota Bontang.

Keberadaan Bontang Reggae Community masih aktif dan bertahan hingga sekarang, ditambah dengan bertambahnya anggota sekitar 70 orang yang terdiri dari beberapa kelompok dan terbagi dibeberapa daerah kota Bontang seperti Lhoktuan, Bontang Baru, Kanaan, Tanjung Laut dan Kanaan. Sentral perkumpulan Bontang Reggae Community bertempat di Bontang Baru, tepatnya di Kedai Kampung Jangkrik yang sangat mudah diakses oleh anggota komunitas. Seiring dengan berjalannya aktivitas musik Bontang Reggae Community, terdapat beberapa kelompok yang masing-masing memiliki cara pandang dan selera musik yang berbeda tetapi masih dalam satu tema yang sama, yaitu Reggae. Masing- masing diantaranya seperti, kelompok Reggae Grill sebagai kelompok musik Reggae dengan sub-genre "Roots Reggae", kelompok Slow Reggae sebagai kelompok musik Reggae dengan sub-genre "Reggaefusion" atau Fusi Reggae, selanjutnya kelompok Reggae Vibe yang merupakan para anggota penikmat musik Reggae sekaligus player Djembe yang bernaung di Bontang Reggae Community

\subsection{Modal Bontang Reggae Community}

Kelompok Reggae Grill merupakan kelompok kecil yang tergabung dalam wadah Bontang Reggae Community. Kelompok ini berada di Lhoktuan tepatnya didalam Gang yang mereka sebut dengan "Gg Brazill”. Perkumpulan kelompok Reggae Grill ini diisi oleh anggota yang sudah sejak dulu mengenal Reggae, saat tergabung dalam Komunitas Musik Bontang di tahun 2012. Terhitung sampai sekarang sekitar 26 orang anggota yang memiliki band Reggae masing-masing, dan 10 orang penikmat musik yang sering bergabung. Beberapa dari mereka yang hanya sebagai penikmat, selalu aktif untuk hadir dalam setiap perform band Reggae di Bontang.

Kelompok ini memiliki beberapa band Reggae yang sampai sekarang masih aktif dalam bermusik yaitu Marry You Wanna, Daun Singkong, THNGT, dan RABS. Reggae Grill memiliki pemahaman dan selera musik Reggae dengan sub-genre "Roots Reggae". Sub-genre ini merupakan salah satu aliran yang mendunia dan dikenal sebagai musik rohani terhadap pemujian kepada "Jah" (Tuhan bagi kaum Rastafari). Selain itu, tema liriknya yang menentang kemiskinan, perlawanan terhadap penindasan pemerintah dan rasisme. Dengan irama musik nya yang santai, serta unsur Reggae yang sangat khas, membuat aliran musik ini menjadi berkarakter. Akar dari sub-genre ini adalah Bob Marley dan Bandnya The Wailers.xx

\subsection{Modal kelompok Reggae Grill}

Pada kelompok Reggae grill terdapat modal material, modal tersebut terdiri dari beberapa kebutuhan yang dapat dipergunakan oleh para aktor di Bontang Reggae Community dalam menjalani pergerakan bermusiknya. Contohnya seperti kepemilikian alat musik dengan tipe dan merk yang lebih berkualitas ataupun yang standart, kendaraan/transpotasi pribadi, dan uang yang didapatkan melalui swadaya dari anggota kelompok Reggae Grill. Disamping itu, mereka juga menggunakan uang swadaya anggota untuk membuat baju kaos Gg Brazil, hal tersebut bertujuan untuk memperlihatkan identitas mereka sebagai kelompok Reggae Grill. Kelompok Reggae Grill juga memiliki modal budaya, modal tersebut bersumber dari lingkungan komunitas dan anggota yang sudah mengenal musik Reggae sejak lama. Ada juga modal budaya yang bersumber dari pendidikan formal, yaitu anggota yang memiliki disiplin ilmu Musikologi atau ilmu budaya sebagai bahan untuk mempelajari seni musik. Kemudian beberapa anggota juga memiliki modal budaya dari lingkungan kerja, salah satunya adalah sebagai guru musik di Sanggar seni. Modal budaya yang dimiliki anggota dalam Sanggar seni musik membangun sebuah modal seni yang dapat dituangkan dalam karya seni musik Reggae. Hal tersebut menjadikan sebuah pemikiran yang dapat diaktualisasikan dalam Bontang Reggae Community agar dapat membentuk eksistensi yang kuat.

\subsection{Kelompok Slow Reggae}

Kelompok Slow Reggae merupakan bagian dari Bontang Reggae Community yang menaungi beberapa band reggae seperti, Brazo, Respect Rast, Delawwa, Up To You. Kelompok ini dinamakan Slow Reggae berdasarkan pengakuan dari anggota kelompok ini sendiri, tetapi mereka tetap mengakui Bontang Reggae Community sebagai komunitas induknya. Kelompok ini bisa dikatakan tergolong anggota baru yang juga aktif di Bontang Reggae Community, kebanyakan dari mereka adalah anak-anak yang masih belia. Kelompok Slow Reggae terbentuk dengan sendirinya sekitar tahun 2015 yang beranggotakan sekitar 8 orang diantaranya adalah Gleen, Juna, Aan, Andre, Halim, dan sisanya dari personil band Up To You. Kelompok Slow Reggae banyak digandrungi anak- anak yang masih remaja dan masih aktif sebagai pelajar SMA. Secara keseluruhan di tahun 2016 sudah beranggotakan sekitar 32 orang, masing-masing diantaranya memiliki band Reggae dan 15 orang hanya sebagai penikmat musik. Tempat berkumpulnya kelompok ini berpindah-pindah, biasanya mereka berkumpul di Angkringan Mas Udin, Lapak Reggae, dan di Kampung 
Jangkrik, tergantung dari kesepakatan mereka untuk berkumpul setiap harinya. Secara musikalitas, subgenre mereka adalah "Reggaefusion" atau biasa disebut dengan Fusi Reggae yang merupakan perpaduan musik Reggae dengan elemen yang berbeda dan memiliki pengaruh dari genre lain. Seperti Hip-hop Reggae, Reggae Jazz, Reggae Blues, dan lainnya. Band-band dari kelompok Slow Reggae lebih sering meng-cover lagu-lagu band Indonesia seperti Tony Q Rastafara, Steven Jam, Momonon, Souljah, hingga mengaransemen lagu-lagu klasik. Selain itu, mereka juga sering membawakan musik SKA dan Rocksteady yang juga berasal dari Jamaika.

\subsection{Modal Kelompok Slow Reggae}

Kelompok Slow Reggae memiliki berbagai modal material berupa alat musik dan studio Band yang biasa disebut GMC (Gangsta Music Crew). Dalam aktivitas bermusiknya, Band-band seperti Brazo, Respect, Delawwa, dan Up To You menggunakan studio GMC untuk latihan. Kemudian modal lain yang dimiliki adalah studio rechording atau biasa disebut studio Option. Mereka mendapatkan potongan harga jika ingin rekaman di studio Option. Alat musik yang dimiliki juga terbilang mahal, mulai dari Gitar Fender Meksiko, Bass Fender jazz custom Amerika, Efek Pedal Board yang komplit, sampai kepada kulit Djembe dari Afrika. Kelompok Slow Reggae juga memiliki berbagai modal budaya berupa pengetahuan dari kelompok lain yang dianut oleh masing-masing individu. Beberapa band dari kelompok Slow Reggae memiliki modal budaya yang bersumber dari komunitas lain seperti BontangDrummer Community, Guitar Perfect League dan sanggar seni budaya. Mereka berhasil memperkaya seni musik salah satunya adalah meningkatkan skill dalam memainkan alat musik. Sehingga sangat mudah bagi mereka untuk meng-cover lagu-lagu Reggae Indonesia maupun Reggae luar negri. Modal budaya lain berwujud pengetahuan akan seni musik juga terbentuk pada aktor kelompok Slow Reggae, hal ini bersumber dari pengetahuan musik yang mereka pelajari diluar. Pengetahuan tersebut juga dikembangkan dalam pergerakan musik mereka masing-masing yang tidak menutup kemungkinan berkembang dengan bantuan dari luar Bontang Reggae Community. Pengetahuan akan musik mampu menjadi modal budaya, maka secara tidak langsung akan mempengaruhi terbentuknya habitus musik dari kelompok Reggae yang bersangkutan

Kelompok ini memiliki modal simbolik berupa gaya berpakaian yang sangat nyentrik dan identik dengan warna merah, kuning, hijau. Selain itu dalam setiap penampilannya selalu mengedepankan eksistensi musik yang mereka tampilkan jauh lebih dominan dari kelompok lain di Bontang Reggae Community, hal ini dikarenakan beberapa band yang ada dalam kelompok Slow Reggae cenderung membawakan lagu-lagu yang sangat familiar dimata penikmat musik Reggae. Kebanyakan dari mereka banyak mengcover lagu-lagu Reggae Indonesia seperti Steven Jam, Tony Q Rastafara, Momonon, Monkey Boots dan masih banyak lagi. Selain itu, mereka juga sering meng-aransemen lagu-lagu dari band lama seperti Koesplus, Panbers dan lagu lama yang digemari oleh kalangan dewasa. Dengan ciri khas mereka yang seperti itu membuat penonton bersorak- sorai untuk ikut mennyanyikan lagu yang mereka bawakan. Mereka dikenal sebagai band yang menarik, dan mudah dikonsumsi masyarakat luas. Namun dalam perjalanannya, kelompok dan band-band yang tergabung dalam kelompok Slow Reggae sangat menghendaki adanya fasilitas yang lebih terstruktur dengan baik dalam berkarya.

\subsection{Kelompok Reggae Vibe}

Kelompok Reggae Vibe merupakan kelompok kecil yang berada dalam naungan Bontang Reggae Community, kebanyakan dari mereka hanya sebagai penikmat musik reggae bukan anak band reggae. Kelompok ini terbentuk karena diawali dengan 4 orang yang suka memainkan alat musik Djembe, seperti Buana, Isal, Putra, dan Igon. Beberapa diantaranya tidak memiliki band Reggae tetapi bisa memainkan alat musik Djembe, hingga akhirnya mereka membentuk kelompok Bontang Reggae Djembe Percussion. Di dalam kelompok Reggae Vibe juga diisi oleh beberapa player djembe dari band Reggae, secara keseluruhan di tahun 2016 kelompok ini berjumlah 7 orang. Mereka tampil dalam acara seni dan acara yang biasa diadakan oleh Bontang Reggae Community. Djembe merupakan alat musik yang berasal dari Afrika, terbuat dari batang pohon mali dan kulit hewan, biasanya memakai kulit kambing atau berbagai macam kulit lainnya. Djembe memiliki suara yang sangat tajam dan khas dilihat dari bentuk djembe yang menyerupai piala, selain itu juga terdapat rongga pada bagian bawah.

\subsection{Modal kelompok Reggae Vibe}

Dalam kelompok Reggae Vibe ada yang memiliki band sendiri ada juga yang tidak memiliki band tetapi ikut bermain Djembe, mereka memberi nama kelompoknya Bontang Reggae Djembe Percussion. Ada beberapa modal material yang mereka miliki untuk mendukung kegiatan mereka yang bersumber dari modal pribadi, Salah satunya adalah alat musik Djembe. Djembe memiliki banyak jenis dan berbeda-beda mulai dari bentuk, bahan dasar, dan kualitasnya. Para anggota yang tergabung dalam kelompok ini secara tidak langsung akan menuntut mereka untuk memiliki Djembe. Tujuannya agar dapat memudahkan mereka dalam 
belajar dan menguasai teknik dalam permainan Djembe. Masing-masing dari mereka memiliki Djembe dengan jenis, dan harga yang berbeda-beda. Semakin bagus kualitas dan bahan yang dipakai pada bahan dasar Djembe tentu semakin mahal harganya.

Kelompok Reggae Vibe juga memiliki modal budaya berupa pengetahuan seni yang dibangun sejak awal pertama kalinya dibentuk. Beberapa dari mereka ada yang sudah sejak lama bermain Djembe, ada juga anggota kelompok yang pernah kuliah di Fakultas Ilmu Budaya Jurusan Etnomusikologi Universitas Mulawarman. Pengetahuan tentang alat musik termasuk Djembe juga masuk didalamnya, selain itu juga ada yang dari awal tertarik dengan Djembe hingga bermain dengan salah satu band Reggae Samarinda mengisi instrumen musik Djembe. Modal budaya yang dimiliki oleh kelompok ini mampu membuat mereka beradaptasi dan belajar bersama.

Selanjutnya, pada kelompok ini juga terdapat modal sosial berupa solidaritas antar anggota kelompok. Selain itu, kelompok ini memiliki jaringan sosial antar anggota komunitas Reggae dari luar kota yaitu Sangatta. Solidaritas kelompok Reggae Vibe ditandai dengan memperbanyak teman-teman sesama penikmat musik Reggae dari berbagai kota di Kalimantan Timur seperti di Samarinda, Balikpapan, Sangatta, Muara Badak, dan Tenggarong.

Kelompok Reggae Vibe memiliki modal simbolik berupa solidaritas antar anggota, hal ini dibuktikan dari keberadaan mereka yang sangat mudah dilacak dan sangat jelas keberadaannya. Kelompok ini dikenal sebagai kelompok yang sangat aktif dalam kegiatan Bontang Reggae Community maupun kegiatan komunitas lain. Namun disisi lain, kelompok ini dipandang sebagai kelompok yang sangat nyentrik dari segi penampilan. Kelompok ini juga aktif latihan bermain Djembe di Kedai Kampung Jangkrik dan lapangan lang-lang pada sore hari. Maka dari itu keberadaan mereka sangat mudah untuk di kunjungi.

\subsection{Habitus Bontang Reggae Community}

Aktor merupakan individu yang mengembangkan kontruksi sosial sebagai tanggapan terhadap kondisikondisi obyektif yang dihadapi saat berada didalam ruang sosial. Dalam artian, aktor merupakan individu yang memainkan perannya serta memperjuangkan posisinya pada ruang sosial melalui berbagai praktik tindakan yang mungkin akan dilakukan. Dalam bertindak, para aktor di dalam suatu arena tertentu akan membangun dan menggunakan habitusnya, agar dapat menghasilkan praktik tindakannya. Pada penelitian ini, aktor dalam praktik Bontang Reggae Communitty terdiri dari kelompok Reggae Grill, kelompok Slow

Reggae, dan kelompok Reggae Vibe. Dengan adanya beberapa kelompok penikmat musik Reggae yang terpencar di daerah kota Bontang tentu memiliki habitus yang berbeda-beda.

Berdasarkan gambaran tabel menyatakan bahwa setiap kelompok yang tergabung dalam Bontang Reggae Community memiliki habitus yang beragam. Habitus atau kebiasaan yang dilakukan oleh para aktor dilakukan dengan maksud dan tujuan yang berbeda-beda, meskipun ada habitus yang sama bukan berarti ketiga aktor tersebut menghasilkan praktik yang sama pula. Habitus yang dilakukan oleh para aktor tentu dipengaruhi dengan ranah sosial yang berbeda sehingga hal tersebut dapat membedakan ketiga aktor yang terlibat dalam Bontang Reggae Community. Habitus juga dapat menghasilkan perilaku dan kebiasaan yang secara terus menerus dilakukan oleh aktor, hingga membentuk sebuah budaya dan berkembang dalam suatu kelompok. Berdasarkan klasifikasi habitus yang ada pada ketiga aktor tersebut, ada salah satu habitus yang dirasa sangat unik dan tidak dimiliki oleh kelompok lain..

Habitus tersebut merupakan habitus yang paling menonjol yang ada pada Bontang Reggae Community, sehingga menjadi pembahasan pokok dan penting dalam melihat habitus aktor. Hal tersebut dapat dilihat pada kelompok Reggae Grill dalam sebuah habitus ngelingkar yang sudah menjadi kebiasaan individu maupun kelompok. Habitus ngelingkar merupakan habitus yang dimiliki kelompok Reggae Grill saat berkumpul sambil berdiskusi dan sharing tentang musik reggae. Disela-sela perkumpulan mereka biasanya diiringi dengan nge- Share rokok atau menggunakan ganja (Gitting) yang didapatkan secara illegal dan tersembunyi, dari anggota kelompok Reggae Grill yang memiliki jaringan khusus untuk mendapatkan ganja dengan mudah Adapun gambaran dari berbagai habitus yang terdapat pada aktor di Bontang Reggae Communtiy. Kemudian habitus yang dilakukan secara bersama-sama dan melibatkan semua kelompok yang ada pada Bontang Reggae Community adalah habitus ngamen, habitus ngamen dibutuhkan saat akan diadakannya acara atau kegiatan komunitas seperti Tribute to Bob Marley, Reggae Party, Road Show, Ngabubureggae, Anniversary, hingga kegiatan bakti sosial dan lainnya. Habitus ngamen dilakukan dengan tujuan untuk mendapatkan dana sukarela yang bersumber dari masyarakat, dengan cara bermusik secara berkelompok dipinggir jalan hingga keliling kota Bontang. Kontribusi anggota baik secara individu maupun kelompok sangat dibutuhkan untuk melakukan habitus ngamen, karena selain sebagai upaya dalam mempertahankan keberadaan Bontang Reggae Community di kota Bontang, habitus ngamen juga dapat meningkatkan rasa kepedulian anggota terhadap sekelilingnya. Selain itu, habitus ngamen juga merupakan salah satu moment atau kesempatan bagi individu dan kelompok dalam berkomunikasi lebih intens sebagai anggota, sehingga kekompakan dan jiwa solidaritas yang tinggi bisa terus terjaga dalam komunitas. 


\subsection{Pergerakan Seni Musik Aktor Bontang Reggae Community}

Ranah Musik Reggae Grill Secara musikalitas musik Reggae memiliki gaya musik yang beraneka ragam, hal ini dikarenakan dengan adanya perkembangan musik Reggae diberbagai negara termasuk di Indonesia. Sub-genre Reggae yang paling mendunia adalah Roots Reggae, sub-genre ini dikenal sebagai musik rohani yang sebagian besar liriknya berisi tentang pemujaan terhadap Jah (Tuhan) bagi kaum Rastafari. Selain itu, lirik dari sub-genre ini juga berisikan pesan tentang perlawanan terhadap bentuk penindasan, rasisme, dan kemiskinan. Ada banyak lagu-lagu dari Bob Marley dan Peter Tosh yang menjadi akar dari sub-genre ini, contohnya seperti lagu Redemption Song, War, Get Up Stand Up, Them Belly Full, (But We Hungry),I Shoot The Sheriff dan masih banyak lagi. Sub-genre Roots Reggae merupakan sebuah ranah musik Reggae yang mempengaruhi aktor didalam kelompok Reggae Grill untuk melakukan pergerakan seni musik melalui karya dan kreatifitas mereka. Hal ini memungkinkan para aktor didalamnya akan saling berinteraksi dengan berbagai pengetahuan yang mereka miliki masing-masing untuk kemudian berkarya.

Aktor dalam kelompok Reggae Grill ini biasanya mendayagunakan identitas kelompok sebagai sarana eksistensi pribadi. Karena dari ruang yang ada pada kelompok musik inilah tidak jarang aktor mendapatkan keuntungan pribadi berupa tawaran untuk bermain dalam panggung hiburan, seperti di Kafe atau dalam setiap event yang membutuhkan band reggae. Pada kelompok Reggae Grill menggunakan musik reggae sebagai media apresiasi dalam menyuarakan kritik sosial terhadap lingkungan, tempat para aktor didalamnya menjalani peran sebagai makhluk sosial yang erat dengan berbagai fenomena disekitarnya. Dengan kondisi semacam inilah memungkinkan para aktor di dalam kelompok Reggae Grill dapat mempertegas identitas kelompok yang mereka bangun.

\subsection{Ranah Musik Slow Reggae}

Pada kelompok Bontang Reggae Community, didalamnya terdapat pula ranah musik yang dipergunakan oleh para aktor dalam bermusik dan berekspresi. Kelompok Slow Reggae memiliki sub-genre "Reggaefusion" atau reggae fusi yang merupakan perpaduan musik reggae dengan elemen yang berbeda dan memiliki pengaruh dari genre lain. Seperti Reggae Pop, Reggae Jazz, Reggae Blues, dan lainnya. Band-band dari kelompok Slow Reggae lebih sering meng- cover lagu-lagu band Indonesia seperti Tony Q Rastafara, Steven Jam, Momonon, Souljah, hingga meng-aransemen lagu-lagu klasik. Selain itu, mereka juga sering membawakan musik SKA dan Rocksteady yang juga berasal dari Jamaika. Slow Reggae lebih mengutamakan kualitas musik melalui aransemen lagu yang dimainkan, serta perpaduan musik Reggae dengan musik lain. Seni musik ini merupakan representasi budaya populis anak-anak muda dari berbagai jenis. Namun pada kelompok musik Slow Reggae ini jarang dimanfaatkan dalam menyampaikan kritik sosial dengan tampilan menyesuaikan kondisi sosial dari masyarakat. Musik ini merupakan suatu kreasi yang dikembangkan oleh anggota Bontang Reggae Community yang memandang dengan transformasi penciptaan ide dan karya aransemen musik Reggae yang lebih populer.

\subsection{Ranah Musik Reggae Vibe}

Kelompok Reggae vibe juga merupakan suatu ranah di Bontang Reggae Community karena kelompok ini terdapat beberapa aktor dengan karakteristik serta aktifitas musik yang berbeda, jika bandingkan dengan kelompok lain yang ada di Bontang Reggae Community. Meskipun secara musikalitas kelompok ini tidak terlalu terarah dalam bermusik, tetapi mereka lebih sering aktif dalam setiap kegiatan ataupun program yang dilakukan komunitas.. Dalam pergerakan musiknya, ranah musik Reggae Vibe ini juga memungkinkan para aktor membangun habitus yang berbeda dari aktor lain. Ranah Reggae Vibe dapat diartikan sebagai ranah kreasi dengan berbagai ekspresi yang bebas dari setiap aktornya. Kelompok Reggae Vibe sebagian besar adalah para penikmat musik Reggae yang bebas melakukan hal apapun, dengan seleranya sendiri tanpa harus fokus dengan satu sub-genre musik Reggae.Sebagian dari mereka juga memiliki kebiasaan bermain alat musik Djembe, dengan membuat suatu kelompok kecil bernama Bontang Reggae Djembe Percussion dengan tujuan untuk menciptakan hal baru dalam berkreasi dibidang seni musik. Pergerakan musik di ranah Reggae Vibe dalam praktik bermusik djembe dilakukan hampir setiap hari disaat sedang berkumpul sore hari, tidak jarang dilakukan oleh beberapa orang saja. Ranah ini juga merupakan aliran baru dalam Bontang Reggae Community dalam mengutamakan pembelajaran serta pemahaman terhadap anggota baru yang masih belia.

\subsection{Korelasi Modal dan Praktik}

Modal merupakan salah satu faktor penunjang keberhasilan yang memungkinkan aktor memenangkan praktik di dalam suatu ranah tertentu. Komunitas Musik Reggae merupakan salah satu ranah musik yang memiliki aktor di dalamnya kemudian menghasilkan berbagai praktik. Praktik dalam ranah musik Reggae tidak akan terjadi tanpa adanya kepemilikan modal yang dimiliki oleh masing-masing individu dan kelompok. Hubungan antara modal dan praktik dapat dilihat dari adanya fungsi modal tersebut dalam menghasilkan sebuah praktik. Dari ketiga kelompok tersebut tentu memiliki modal yang berbeda sesuai 
kemampuannya, yang kemudian menghasilkan praktik yang berbeda pula. Ketika suatu kelompok atau individu memiliki modal yang maksimal, maka akan maksimal pula praktik yang dihasilkan kelompok tersebut.

Dengan adanya korelasi antara modal dan praktik dapat dilihat perbandingan antara ketiga kelompok yang ada dalam Bontang Reggae Community. Masing- masing kelompok memiliki modal yang bersumber dari usaha yang mereka lakukan. Dari segi material yang memenangkan praktik didalam ranah musik Reggae yaitu kelompok Slow Reggae, hal ini dikarenakan kepemilikan modal material yang dimiliki kelompok Slow Reggae lebih mumpuni dan berkualitas untuk menciptakan musik yang maksimal demi kepentingan Entertainment, selain itu juga dapat memperluas kesempatan untuk mendapatkan tawaran Perform band yang maksimal. Berbeda dengan kelompok Reggae Grill yang hanya memiliki modal material berupa alat musik alakadarnya yang membuat kelompok ini kurang dari segi materi. Tetapi dari segi budaya dan simbolik, kelompok Reggae Grill mampu membentuk suatu identitas Reggae yang murni dan sesuai dengan musik reggae pada umumnya, mereka menganggap musik Reggae bukan hanya sekedar musik tetapi ada unsur budaya yang terkandung didalamnya sebagai musik perlawanan dan pemberontakan dari segala bentuk penindasan. Sedangkan kelompok Reggae Vibe lebih kepada solidaritas sesama anggota Reggaeman yang menjadi bentuk praktik dari hasil modal sosial, karna kebanyakan dari kelompok ini hanya sebagai penikmat musik dan kelompok pemain Percussi Djembe yang mengedepankan solidaritas kelompok

\subsection{Praktik Sosial Komunitas Musik Reggae di Kota Bontang}

Komunitas Musik Reggae (Bontang Reggae Community) merupakan sebuah komunitas yang berangkat dari pengetahuan sekelompok anak muda pecinta musik Reggae yang dulunya tergolong musik minoritas di Kota Bontang. Pada awal perkembangannya, para aktor berkumpul dengan sebuah tujuan yang sama dan didasari dengan niat yang tinggi untuk membentuk sebuah komunitas hingga membesarkannya. Komunitas ini bergerak dan saling membangun pengetahuan untuk belajar bersama dalam hal musik agar dapat mempresentasikan tujuan bersama. Diluar dari pada itu, komunitas ini terbentuk dikarenakan hendak meluangkan waktunya untuk melakukan kegiatan positif melalui kreatifitas musik sebagai hobi dan kecintaannya terhadap musik reggae.

Komunitas ini sering mengadakan acara besar dan pentas musik bergenre Reggae di Kota Bontang, hanya saja mereka sering terkendala dengan dana yang di butuhkan untuk menyelenggarakan acara tersebut selalu kekurangan dan susah untuk mencari donatur. Kemudian perijinan untuk acara dari kepolisian juga menjadi faktor penghalang bagi mereka untuk berkreasi dan menyalurkan karya musik yang mereka miliki. Berbagai usaha yang dilakukan seperti "Ngamen" dan mengadakan Roadshow dipinggir jalan, merupakan suatu bentuk pergerakan yang dilakukan untuk menyalurkan kepedulian mereka terhadap musik. Meski terhalang dengan itu semua, sama sekali tidak menyurutkan semangat mereka untuk terus berusaha dan berjuang demi pencapaian eksistensi dan pengakuan terhadap publik akan keberadaan mereka. Maka melalui skema praktik sosial Bourdieu, pergerakan Bontang Reggae Community sendiri dipandang sebagai bentuk praktik sosial. Praktik sosial tersebut digambarkan melalui pembahasan habitus, modal, dan ranah yang ada dalam Bontang Reggae Community.

Bontang Reggae Community terbentuk dari tiga aktor didalamnya yaitu kelompok Reggae Grill, Slow Reggae, dan Reggae Vibe. Dari ketiga aktor tersebut memiliki habitus yang beragam dalam aktifitas bermusiknya. Pada kelompokReggae Grill yang menggunakan sub-genre "Roots Reggae" sebagai ranah musik mereka, hingga melakukan berbagai macam habitus untuk menghasilkan praktik, sampai kepada pembentukan identitas dan karakter musik yang berhasil mereka ciptakan. Begitupun pada kelompok Slow Reggae yang kurang lebih memiliki habitus yang sama dengan kelompok Reggae Grill, yang membedakannya adalah sub-genre musik Reggae yang digunakan yaitu "Reggaefusion", melalui habitus yang dilakukan dan berhasil menciptakan aransemen musik yang berkualitas. Kemudian kelompok Reggae Vibe dengan ranah kehidupan sosial yang berbeda dan membentuk suatu habitus yang menghasilkan praktik solidaritas kelompok khususnya kepada sesama anggota didalam Bontang Reggae Community.

Praktik sosial Bontang Reggae Community tentunya didukung oleh berbagai modal yang menyertai aktivitas bermusik. Modal merupakan akar kekuatan yang dimiliki oleh individu/kelompok untuk perjuangan dalam ranah tertentu. Keempat modal fundamental berdasarkan tipifikasi modal menurut Bourdieu, berhasil dimiliki dan diperjuangkan oleh setiap kelompok didalam komunitas. Keempat modal tersebut didapatkan dengan cara yang berbeda-beda sesuai dengan kemampuan aktor, modal tersebut berupa modal simbolik, modal budaya, modal ekonomi, dan modal sosial.

\section{KESIMPULAN}

Dari uraian diatas, dapat dilihat bahwa praktik sosial dalam pergerakan musik Bontang Reggae Community sebagai salah satu kelompok musik di Kota Bontang dapat berjalan baik dan lebih cepat dibanding komunitas lain. Karena, setiap kelompok yang ada pada Bontang Reggae Community memiliki 
habitus dan modal yang terakumulasi secara tepat dalam ranah musiknya. Hal ini menjadikannya semakin kompleks modal yang dimiliki oleh para aktor, maka semakin kompleks pula habitus yang terbangun oleh aktor tersebut dalam pergerakan musiknya di Bontang. Praktik sosial komunitas musik Reggae di kota Bontang dalam perkembangannya dijalankan melalui adanya reproduksi budaya, habitus, modal, dan ranah yang mendukung aktor melakukan pergerakan musiknya. Reproduksi budaya kelompok Reggae Grill Pertama, ciri khas musik yang memunculkan sebuah identitas antara kelompok ataupun band yang kemudian menjadi khas dan berkarakter bagi kelompok tersebut, kedua pesan moral yang terkandung didalamnya yang kemudian membangun stigma positif dari masyarakat. Ketiga, konsep latihan atau ngulik lagu yang benarbenar matang sebelum tampil berfungsi untuk meningkatkan kualitas band. Keempat, penggunaan ganja yang digunakan sebagai media penghantar rileksasi dan kegembiraan bersama disaat melingkar. Berbeda dengan kelompok Slow Reggae yang memiliki reproduksi budaya dengan ciri khas musik yang mengedepankan popularitas seni musik, melalui modifikasi dan aransemen musik Reggae yang dikolaborasikan dengan genre musik lain. Hal tersebut bertujuan untuk meningkatkan kualitas musik agar mudah dikonsumsi masyarakat, dengan cara seperti itu maka akan mendukung penuh perkembangan musik kelompok Slow Reggae dalam pergerakan seni musiknya.

\section{DAFTAR PUSTAKA}

Bungin B, 2001, Metodologi Penelitian Kualitatif, Penerbit PT. Raja Grafindo Persada, Jakarta.

George Ritzer \& Douglas J Goodman, 2008, Teori sosiologi, Penerbit PT kreasiwacana.

Helmi Y Aska, 2005, Rasta, Reggae, dan Revolusi, Kepak

Jube', 2007, Reggae: Musik, Spritual dan perlawanan, PT O2, Yogyakarta.

Jube', 2007, Song of Freedom, Eja Publisher

Nando Baskara, 2009, Bob Marley, Spirit Of Freedom, PT Narasi, Yogyakarta.

Pierre Bourdieu, 2005, (Habitus $\times$ Modal) +Ranah - Praktik: Pengantar paling konprehensif kepada pemikiran Pierre Bourdieu, PT Jalasutra.

Pierre Bourdieu, 2010, Arena Produksi kultural, Penertbit PT Kreasi Wacana. Soerjono Soekanto, 2012, Sosiologi Suatu Pengantar, Penerbit PT Raja GrafindoPersada, Jakarta.

Miftahul Jannah, Nim. 11540004 (2015) Musik Reggae Sebagai Pembentuk Identitaa Sosial (Studi Analisis Pengaruh DOXA terhadap komunitas Reggae Longharjo di Desa Harjodowo Kecamatan Kuarasan, Kabupaten Kebumen). Skripsi, UIN Sunan Kalijaga Yogyakarta.

Bayu Sugita. 2013. "Rastafarian (Gaya Hidup Rastafarian Sebagai Bentuk Eksistensi Subkultur Reggae)”, (Online), (Journal.unair.ac.id, diakses pada tanggal 10 Desember 2017). 